BLS 32, No 1 2006. DOI: http://dx.doi.org/10.3765/bls.v32i1.3463 (published by the Berkeley Linguistics Society and the Linguistic Society of America)

\title{
A Metaphor of Static Temporal "Location" in Wolof and English: Metonymy, Motivation, and Morphosyntax ${ }^{*}$
}

\author{
KEVIN EZRA MOORE \\ San José State University
}

\subsection{Introduction}

This paper continues a trend of research that examines the precise conceptual claims made by theories of space-to-time metaphors (e.g. Clark 1973, EngbergPedersen 1999, Lakoff \& Johnson 1980, Matlock et al. 2005, Moore 2004, 2006; Núñez \& Sweetser 2006, Traugott 1975). It will begin by discussing the exact mapping and experiential basis involved in the static temporal metaphor instantiated by expressions like It gets hot in October, offering an alternative to the account found in Lakoff \& Johnson 1999. Then the discussion will turn to the relations between metaphor, metonymy, and grammar in Wolof (Niger-Congo, Senegal). Wolof seems to use a metaphor of static temporal location in contexts where English would not, as in (1) below, ${ }^{1}$ and this is plausibly related to a generally greater use of locative morphosyntax in Wolof than English. (A literal translation of the example is given in double quotes under the Wolof data, followed by a more idiomatic translation in single quotes.)

\footnotetext{
"I would like to thank Paap Alassane Sow ("APS") for Wolof data and guidance.

${ }^{1}$ Following is a list of abbreviations used in this paper: 1 'first person' (etc.); AND 'andative'; att. 'attested in use'; AV 'altered valence'; CAUS 'causative'; COND 'conditional'; DEF 'definite'; DIST 'distal'; FOC 'focus'; GEN 'genitive'; IMPF 'imperfective'; INDEF 'indefinite'; LOC 'locative'; LOCPREP 'locative preposition'; MID 'middle voice'; NEG 'negation'; OBJ 'object'; PD 'possessed'; PERF 'perfect'; PL 'plural'; PRSNTTV 'presentative'; REL 'relativizer'; SBJT 'subject'; SFOC 'sentence focus'; VC 'verbal complement' (a morpheme that marks a construction in which the following verb is a complement of the preceding one).
} 
Kevin Ezra Moore

(1)

Fajarfekkul Musaa ci néeg bi, waaye

dawn become.co-located.with:NEG Musaa LOCPREP room the but

laata muy maase jot na fee duggu

before 3.SBJT:IMPF become.even reach PERF. 3 here:VC enter:MID

ci néeg bi ba tegu

LOCPREP room the to.the.point.of put:MID

ci yoonu tool wi.

LOCPREP way:PD fields the

"Dawn didn't find Musaa in the room, but before it evened out, he reached in here to enter the room to the point of getting on the way to the fields." 'Musaa wasn't in the room when dawn broke, but before it ran its course he managed to enter the room and then start off to work.' [APS. Constructed] (Moore 2000)

Scholars sometimes speak of a metaphor called TIME IS SPACE (e.g. Fauconnier \& Turner 2008). Stated in this way, the metaphor is a very broad generalization in need of further specification. Does it mean that anything spatial maps onto anything temporal? In this paper I will try to take a step towards understanding how spatial concepts map onto temporal concepts by looking at a specific spaceto-time mapping and its presumed motivation.

\subsection{Background: Metaphors That Construe Time as Space}

There is an extensive tradition of research on metaphors that construe "when" relations as "where" relations (see above references). Most of this research has focused the Moving Ego and Moving Time metaphors. The Moving Ego metaphor (i.e. "Moving Observer" in Lakoff \& Johnson 1999) construes the experiencer of time ("ego") as moving forward, and the times themselves as locations relative to which ego moves (Boroditsky 2000; Clark 1973; Fillmore 1997[1971]; Lakoff \& Johnson 1980; Moore 2000, 2006; Núñez \& Sweetser 2006; etc.). Here are some linguistic expressions that instantiate Moving Ego: Venezuela is headed for a major political crisis in the months ahead. [S.F. Bay Guardian; 4 Aug 99, p. 29]. Let's set up a time to meet when we get a little farther down the road. The Moving Time metaphor construes ego as stationary and times as moving relative to her (see above references). Here are some examples: The time has comel arrived/ passed. By now Mrs. Thompson realized the problem, but Christmas was coming fast.

\subsection{Beyond Moving Ego and Moving Time}

In previous work on temporal metaphor, Lakoff \& Johnson (1999:153) have proposed that “...[E]vents viewed as being instantaneous or as single unextended entities are conceptualized via that part of the Moving Observer [i.e. Moving Ego] metaphor that conceptualizes time as being located at time locations, as in a sentence like [2a]" [italics in original]. Lakoff \& Johnson cite the examples in (2) below. 


\section{A Static Temporal Metaphor in Wolof and English}

(2) a. The execution occurred at 10:06 p.m. [Ibid:153]

b. She arrived on time. He left at 10 o'clock. [Ibid:146]

Lakoff \& Johnson's proposal is appealing because there is an abundance of data that clearly point to the existence of the Moving Ego metaphor, and the account of its experiential basis is solid (see below, and e.g. Clark 1973; Lakoff \& Johnson 1999 Chapter 10). However, I would like to claim that since expressions such as those in (2) do not involve either a particular point of view or metaphorical movement, a metaphor that does not require movement or a particular point of view would be better motivated by the data. What the expressions in (2) provide evidence for is simply a metaphor in which places map onto times (cf. Grady 1997, Moore 2006).

As an alternative I propose that a metaphor called A TIME IS A PLACE predicts the semantics and syntax of expressions such as those in (2) better than Moving Ego does, if we assume a relatively direct correspondence between source frame, target frame, and linguistic coding. ${ }^{2}$ The mapping of A TIME IS A PLACE is summarized in (3) below.

(3) The Mapping for A TIME IS A PLACE

\begin{tabular}{|l|c|l|}
\hline SOURCE FRAME/DOMAIN & & TARGET FRAME/DOMAIN \\
\hline A physical entity. & $\rightarrow$ & An event or state. \\
\hline A place. & $\rightarrow$ & A time. \\
\hline Different places & $\rightarrow$ & Different times. \\
\hline Being at a place. & $\rightarrow$ & $\begin{array}{l}\text { Occurring/obtaining (partially) simul- } \\
\text { taneously with a time. }\end{array}$ \\
\hline
\end{tabular}

Data that instantiate A TIME IS A PLACE are also available in Wolof, showing that this metaphor is not restricted to a particular language or language family:

$$
\begin{array}{lll}
\text { Dugub }, \quad \underline{c i} & \text { lolli lay } & \tilde{n} \text { or. } \\
\text { guinea.corn LOCPREP } & \text { lolli NONSBJT.FOC.3:IMPF be/get.ripe } \\
\text { 'Guinea corn, it gets ripe in lolli.' (Lolli is a season.) [s XW, Ba:62 }]^{3}
\end{array}
$$

Taking it as established that A TIME IS A PLACE motivates data such as those in (2) and (4) better than Moving Ego does, what remains is to show that A TIME IS A PLACE has a plausible experiential basis.

\subsection{The Experiential Basis of A TIME IS A PLACE}

One of the central ideas in the theory of conceptual metaphor is experiential basis (Lakoff \& Johnson 1980:19). The experiential basis of a metaphor is an experi-

\footnotetext{
${ }^{2}$ I speak of frames instead of domains (see Moore 2006), but the difference is not crucial here.

${ }^{3}$ The lowercase $s$ included in the bracketed notation below examples means that the speaker is a male from rural Saloum (Senegal) and that the example is not constructed.
} 


\section{Kevin Ezra Moore}

ence in which the source-frame and target-frame concepts of the metaphor correlate in experience. For example, as discussed in Lakoff \& Johnson (1999:152) (see Sweetser 1988), Moving Ego is motivated by experiences in which a future event is expected to occur at a location towards which ego is moving, and at which she expects to arrive. Evidence for the salience of this correlation comes from metonymic linguistic expressions that simultaneously refer to both the spatial and the temporal concepts that are relevant to the metaphor (cf. Norvig 1988). An example of such an expression would be There is trouble ahead, said in a context in which it means both that there is trouble farther in ego's (spatial) direction of travel and that there is trouble in ego's future.

The correlation that motivates A TIME IS A PLACE obtains between the time of an event and the place at which it happens. Evidence for the salience of such a correlation comes from examples such as the following Wolof sentence and its English translation, each of which has the relevant spatial and temporal meanings.

$$
\text { Foo ko fekk mu ne-xulaas. }
$$

where:you 3.OBJ become.co-located.with 3.SBJT be.drunk.as.a.skunk "Wher[ever] you met him he was drunk as a skunk."

'He was always drunk as a skunk.' [Cissé 1994:36] (Moore 2000)

In example (5) above, there is a metonymic inference from places at which the person was drunk to times when he was drunk. The metonymy - A PLACE FOR A TIME - is evidence for a salient correlation between the times when and places where events occur. It is similarly involved in the next example from English, in which the locative expression where is used to refer to an event, viz. a party.

When the summer boarders and the Northern visitors undertake to give one, it is a comparatively staid affair, where due regard is had for one's wearing apparel, and where there are servants to do the hardest. [Dunbar 1899]

Similarly, the locative expression at can be used to talk about a meeting in a context in which meeting refers to both the place where and the time when a person spoke.

She spoke at two successive meetings.

Finally, in (8) below, the expression everywhere refers to the different settings at which events of talking happened. (This may not be a good example of metonymy, but it does show that a place-time correlation is salient.) 


\section{A Static Temporal Metaphor in Wolof and English}

... Everywhere .. we've been,... in the past several years,.. everybody's talking about how,.. $(\mathrm{H})$ the weather just .. isn't .. normal. [Santa Barbara Corpus of Spoken English. File 003, beginning at 507.66. Transcription conventions: (H) 'inhalation'; ... 'medium pause'; .. 'short pause'.]

We have seen from the examples in this section (Section 1) that the metaphor A TIME IS A PLACE can construe a time as a place independently of motion or ego's point of view. This is evidence that A TIME IS A PLACE exists independently of Moving Ego. However, the two metaphors are fully consistent with one another, as discussed in Lakoff \& Johnson (1999), and in many if not most cases A TIME IS A PLACE involves ego's point of view. In the remainder of the paper we will investigate the instantiation in Wolof of A TIME IS A PLACE and the related metonymy A PLACE FOR A TIME.

\section{Language-specific Phenomena in Wolof}

\subsection{Bound Morphemes Relevant to Location in Wolof}

Before discussing the metaphor and metonymy data from Wolof, it is appropriate to look briefly at some of the morphology that plays a role in the data. The table in (9) displays bound morphemes in Wolof that are relevant to location (Sauvageot 1965).

(9) Bound Morphemes in Wolof that are Relevant to Location

$f$ - location

$-\boldsymbol{i} \quad$ proximal deixis (semantically unmarked relative to distal deixis)

$-\boldsymbol{a}$ distal deixis

$\boldsymbol{- u} \quad$ deictically undetermined

Examples of words containing these morphemes: $f i$ 'here', $f a$ 'there', $f u$

'where'. These are clitics that tend to appear before the content verb.

$\boldsymbol{e}(\boldsymbol{e})$ This is a general argument-adding suffix. I gloss it LOC where locative arguments are added. Otherwise I gloss it AV for altered valence.

-(j)i The action of the verb is done away from the deictic center; i.e., andative

Before proceeding, it should be pointed out that temporal concepts can be talked about in Wolof without the use of locational morphosyntax, as in the following example:

$$
\begin{aligned}
& \text {...nekk-oon fi } \underline{b i} \text { lii } d i \quad \text { am ... } \\
& \text { be.located-PAST here when this IMPF happen } \\
& \text { '...was here when this was happening. [Jen 1992:39] }
\end{aligned}
$$

In example (10), $f i$ 'here' has a purely spatial meaning, and the notion 'when' is expressed with $b i$, which is not a locational morpheme (though $b$ - does mark the most general "thing" noun class). 


\section{Kevin Ezra Moore}

\subsection{The metaphor A TIME IS A PLACE in Wolof}

Although Wolof and English both have A TIME IS A PLACE, some Wolof constructions that instantiate this metaphor do not have equivalent metaphorical expressions in English. Thus the metaphor appears to be more productive in Wolof. For a metaphor to be more productive than another is to occur in more contexts (i.e. occur more freely; cf. Aronoff and Fudeman 2005:241). After looking at the metaphor data we will go on to study the metonymy A PLACE FOR A TIME, which provides evidence for the experiential basis of the metaphor.

In (11) below, the time during which Mben was cooking dinner is referred to in explicit spatial terms and then repeatedly indexed with locative $f i$ throughout the sentence. The underlined locative expressions in (11) are all used metaphorically in that that they refer to a time and not a place.

Diggantefi mu taal-e reer ak $f i$ mu noppee, between where 3.SBJT light-LOC dinner and where 3.SBJT finish:LOC Mbeen toj na fi leket, dumafi doomji, Mben smash PERF.3 here gourd slap here child the, dëgg fib cuuj ba mu dee. step.on here:INDEF chick to.the.point.of 3.SBJT dead "Between where she started dinner and where she finished, Mben smashed a gourd here, slapped her child here, and stomped a chick to death here." 'Between the time she started dinner and the time she finished, Mben broke a gourd, slapped her child, and crushed a chick to death underfoot.' [Jeๆ 1992:62]

In example (1) at the beginning of the paper, the brief period of time in which Musaa entered and exited the room is indexed as $f i$ 'here'. (The form is fee in the example because the $-i$ of $f i$ has coalesced with the following $a$ ' $\mathrm{VC}$ '; i.e., fee $=$ $f i+a$.) In (12) below, the period of time during which the tea got cold is referred to as $f i$ 'here'. According to my consultant, Mr. Sow (who uttered the sentence spontaneously), $f i$ has temporal and not spatial reference in this example. However, metonymy cannot be entirely ruled out, since the place of utterance (which presumably could be referred to with $f i$ 'here') is also the place where the tea got cold.

Ma tàngalaat ko ndax jot na fee sedd. 1.SBJT be.hot:CAUS:again 3.OBJ because reach PERF.3 here:vc be.cold "I'll heat it up again because it has reached to be cold here." 'I'll heat it up again because it has gotten cold' (Talking about a cup of tea. The construction conveys the idea that there's been enough time for the tea to get cold [062599].) [att.] [APS, Lu:101]

The examples in (1), (11), and (12) show that A TIME IS A PLACE is more productive in Wolof than in English, at least in the observed (linguistic and physical) 


\section{A Static Temporal Metaphor in Wolof and English}

contexts. In the next section, we will see evidence that the metonymy A PLACE FOR A TIME is also more productive in Wolof.

\subsection{The Metonymy A PLACE FOR A TIME in Wolof}

This section begins with examples that show a kind of metonymy-to-metaphor continuum from A PLACE FOR A TIME to A TIME IS A PLACE in Wolof. The metonymy is evidence for the experiential basis of the metaphor (cf. Grady \& C. Johnson 2002; C. Johnson 1999; Lakoff \& Johnson 1980, 1999). The continuum also suggests that the metonymy may have contributed to the conventionalization of the metaphor, since this kind of continuum is characteristic of semantic change, which has been observed to occur via gradual shifts that are supported by context (Heine et al. 1991; Hopper \& Traugott 1993). Indeed, various scholars have hypothesized that metaphor (at least in some cases) develops from metonymy (see for example Barcelona 2002; Dirven \& Pörings 2002; Radden 2002). However, I do not have spontaneous data supporting a role for metonymy in the conventionalization of A TIME IS APLACE.

Example (13a) below simultaneously means that the rain began to fall on a person at a particular place where she was thinking about her home and that it began to fall on her as she was thinking about her home (cf. Emanatian 1992; C. Johnson 1999; Norvig 1988). In (13b) a spatial reading of the locative $f a$ is not prominent, but metonymy cannot be ruled out entirely. Example (13c), which does not allow a spatial reading of $f a$, represents the metaphor end of the continuum (Moore 2000:195).

\section{a. (Metonymy)}

Fa mu toog-e di fàttaleku dëkkam

where 3.SBJT sit-LOC IMPF remember home:GEN

la ko taw bi fekk.

NONSBJT.FOC.3 3.OBJ rain the become.co-located.with

"Where she sat thinking of her home is where the rain became colocated with her." "The rain found her at the spot where she sat thinking about her home.' 'It began to rain on her where/as she sat thinking of her home.'[APS, 021899. Constructed]

b. (More metaphoric than metonymic)

\section{Fa mu toog-e di fàttaleku dëkkam la}

where 3.SBJT sit-LOC IMPF remember home:GEN NONSBJT.FOC.3

taw bi tàmbale.

rain the start

"Where she was sitting thinking of her home is where the rain started." 'As she was sitting thinking of her home, the rain started.' 'It was at a moment when she was sitting thinking of her home that the rain started.'[APS, 021899. Constructed.] 


\section{Kevin Ezra Moore}

c. (Metaphoric and not metonymic)

$$
\begin{aligned}
& \text {... weer wi fim teroo ak fim } \\
& \text { moon the where:3.SBJT appear:LOC and where:3.SBJT die-LOC } \\
& \text { "the moon, where it appears and where it dies." } \\
& \text { 'when the moon appears and when it disappears.' (The speaker is } \\
& \text { saying that there is a calendar that gives this information on the } \\
& \text { moon/month.) [s V tape] }
\end{aligned}
$$

Next are more examples of A PLACE FOR A TIME. In the first example the speaker refers directly to the place where he is talking and metonymically to the time when he is talking.

a. Mënuleen ko, ngeen ni coww ñibbi, te du tax ma yóbbu Ndeela, 'If you can't do it [i.e. keep quiet], then go straight home, but that won't make me take Ndela'

$$
\begin{aligned}
& \text { ndax ba fii may wax-e, jabari } \\
& \text { because as.far.as here 1.SBJT:IMPF } \\
& \text { jaambur lalk-LOC wife:of } \\
& \text { someone.else 3.NONSBJCT.FOC } \\
& \text { "because all the way to here where I am talking at, she is someone } \\
& \text { else's wife". 'because up to this point as I speak, she is still someone } \\
& \text { else's wife' [Jen 1992:32] }
\end{aligned}
$$

In the next example, the place where the speaker smokes stands for instances of smoking.

b. Musuloo gis fu ma tux-e. have.ever.experience:NEG.2 see where 1.SBJT smoke-LOC

"You have never seen where I smoke at." 'You have never seen me smoke anywhere.' 'You have never seen me smoke.' [APS, Hai:33]

A PLACE FOR A TIME and A TIME IS A PLACE both seem to be more productive in Wolof than in English. This can be related to a more general phenomenon in which (literal) locative marking is productive in Wolof.

\subsection{Linguistic Coding of Location in Wolof}

The pervasiveness of locational marking in Wolof may contribute to an explanation of the productivity of A PLACE FOR A TIME and A TIME IS A PLACE in this language if "frequent use of forms directs attention to their functions" as suggested by Slobin (2003) (cf. Whorf 1956). The data in (15) below suggest that location is highly codable and frequently mentioned in Wolof (cf. Slobin ibid). To be codable is to be accessible and easy to process/express. For example a notion that is expressed by inflection (such as number in English) is highly codable. Below 


\section{A Static Temporal Metaphor in Wolof and English}

we see that the same locational morphemes that play a role in the metonymic and metaphoric expressions we studied above also occur in a wide variety of other locational contexts, sometimes several per sentence.

In (15a) below we see a form in locative $f$ - as the relative pronoun in a "headless" relative clause.

a. Butolloo $f u$ sore $\tilde{n} u$ xàmme ko ndax koll bi. if measure:COND where be.far they recognize 3OBJ because paunch the "If one is located where is far, they recognize him because of the pot belly." 'He is recognizable from a distance because of his pot belly.' [Fal et al. 1990 under koll (b)]

In (b), the -e suffix on the verb lekk 'eat' marks the fact that the verb is taking a locative argument $f a$ 'there', in addition to the expected agent and patient.

b. Waaw, fa laa lekk-e ceebujën yes there NONSBJT.FOC: 1 eat-LOC rice:of:fish

'Yes, there is where I ate rice with fish.' [Church 1981:325]

Example (c) below has an "extra" locative expression $f i$ in a context in which an English speaker would not mention location. (Munro \& Gaye 1997:33 list dàq fi "be better here" as an idiom meaning 'be good at'.)

c. Tenee $f i$ dàq dow!

cheetah:SBJT.FOC here be.better run

"The cheetah is better at running here"

'The cheetah is really fast!' [Fal et al. 1990 under tene $(\mathrm{m})$ ]

The next example, which is an idiom, shows the locative $f$-being repeated for emphasis in a construction that exploits the existence in Wolof of the more emphatic fii and the less emphatic $f i$ (both meaning 'here').

d. Fii, wund du fi naan-e ñeex.

here cat IMPF:NEG here drink-LOC sauce

'A cat doesn't drink sauce here.' (I.e. 'You are in my element; you don't have the power.') [Cissé et al. 1982:58]

The next sentence exemplifies the fact that it is possible to code location multiple times in a Wolof sentence. Each locational morpheme is underlined. The underlined $a$ 's mark distal deixis. 


\section{Kevin Ezra Moore}

e. Caat mu góor ma moom, ma- nga fége-ji youngest REL be.male DEF:DIST him 3-PRSNTTV:DIST settle-AND ca taax $y \underline{a}, \quad d i \quad f a$ dawal saret, LOCPREP:DIST block.buildings PL.DEF.DIST IMPF there drive cart ba jell fa jabar féete fa. to.the.point.of take there wife be.situated there "The youngest son, he went and settled in the city, driving a cart there, and taking a wife there, situating himself there." [Jeף 1992:30]

The data in (15) above suggest that Wolof grammar encourages speakers to pay attention to location. Many of the linguistic constructions in these data, such as those that employ locative $f$-, deictic $-i$ or $-a$, and the locative-argument marking $e$, are the same as the ones that are involved in A TIME IS A PLACE and A PLACE FOR A TIME. It is thus plausible that Wolof grammar plays a role in facilitating the use of these metaphoric and metonymic structures. Obviously, more languages need to be examined before this claim can be evaluated satisfactorily.

\subsection{Summary}

I have argued that linguistic expressions in which temporal relations are spoken of in terms of static location instantiate the metaphor A TIME IS A PLACE. In this metaphor contrasting places map onto contrasting times. The argument for the experiential basis of A TIME IS A PLACE appealed to the metonymy A PLACE FOR A TIME. I claimed that the assumed productivity of the metonymy and the metaphor in Wolof may have to do with locational morphosyntax and codability of location in that language.

\section{References}

Aronoff, Mark \& Kirsten Fudeman. 2005. What is morphology? Malden MA: Blackwell.

Barcelona, Antonio. 2002. Clarifying and Applying the Notions of Metaphor and Metonymy within Cognitive Linguistics: an Update. In Dirven and Pörings (eds.). 207-277.

Boroditsky, Lera. 2000. Metaphoric Structuring: Understanding Time through Spatial Metaphors. Cognition, 75: 1-28.

Church, Eric. 1981. Le Système Verbal Du Wolof. Dakar: FACUlTE DES LETTRES ET SCIENCES HUMAINES de l'UNIVERSITÉ DE DAKAR.

Cissé, Mamadou. 1994. Contes wolof modernes. Paris: L'Harmattan.

Cissé, Mame Thierno; Mammadu Guèye \& Mangoné Touré. 1982. Proverbes wolof. Dakar: Centre de Linguistique Appliquée de Dakar.

Clark, Herbert. 1973. Space, Time, Semantics, and the Child. In T. E. Moore, ed., Cognitive Development and the Acquisition of Language. New York: Academic Press. 27-63 


\section{A Static Temporal Metaphor in Wolof and English}

Dirven, René \& Ralf Pörings (eds.). 2002. Metaphor and Metonymy in Comparison and Contrast. Berlin: Mouton de Gruyter.

Dunbar, Alice. 1899[1969]. The Goodness of St. Rocque and Other Stories. New York: Dodd/Mead. (Available online through The Gutenberg Project. October, 1996 [Etext \#688].)

Emanatian, Michele. 1992. Chagga 'Come' and 'Go': Metaphor and the Development of Tense-Aspect. Studies in language 16, 1-33.

Engberg-Pedersen, Elisabeth. 1999. Space and Time. In Jens Allwood \& Peter Gärdenfors, eds., Cognitive Semantics: Meaning and Cognition. Amsterdam: John Benjamins. 131-152

Fal, Arame; Rosine Santos \& Jean Léonce Doneux. 1990. Dictionnaire woloffrançais. Paris: Karthala.

Fauconnier, Gilles \& Mark Turner. 2008. "Rethinking Metaphor”. In Ray Gibbs, ed., The Cambridge Handbook of Metaphor and Thought. Cambridge University Press. 53-66.

Fillmore, Charles. 1997 [1971]. Lectures on Deixis. Stanford: CSLI Publications.

Grady, Joseph. 1997. Foundations of Meaning: Primary Metaphors and Primary Scenes. Ph.D. diss., University of California, Berkeley.

Grady, Joseph \& Christopher Johnson. 2002. Converging evidence for the notions of subscene and primary scene. In Dirven \& Pörings (eds.) 533-554.

Heine, Bernd; Ulrike Claudi \& Friederike Hünnemeyer. 1991. Grammaticalization. Chicago: The University of Chicago Press.

Hopper, Paul \& Elizabeth Closs Traugott. 1993. Grammaticalization. Cambridge: Cambridge University Press.

Jeף, Maam Yunus. 1992. Aawo bi. Dakar: IFAN Cheikh Anta Diop.

Johnson, Christopher. 1999. Constructional Grounding: the Role of Interpretational Overlap in Lexical and Constructional Acquisition. Ph.D. diss., University of California, Berkeley.

Lakoff, George \& Mark Johnson. 1980. Metaphors We Live By. Chicago: University of Chicago Press.

Lakoff, George \& Mark Johnson. 1999. Philosophy in the Flesh: The Embodied Mind and Its Challenge to Western Thought. New York: Basic Books.

Matlock, Teenie; Michael Ramscar \& Lera Boroditsky. 2005. On the Experiential Link between Spatial and Temporal Language. Cognitive Science 29, 655664.

Moore, Kevin. 2000. Spatial Experience and Temporal Metaphors in Wolof: Point of View, Conceptual Mapping, and Linguistic Practice. Ph.D. diss., University of California, Berkeley.

Moore, Kevin. 2004. Ego-based and Field-based Frames of Reference in Space to Time Metaphors. In Michel Achard \& Suzanne Kemmer, eds., Language, Culture, and Mind. Stanford, CA: CSLI Publications. 151-165

Moore, Kevin. 2006. Space to Time Mappings and Temporal Concepts. Cognitive Linguistics 17(2):199-244. 


\section{Kevin Ezra Moore}

Munro, Pamela \& Dieynaba Gaye. 1997. Ay Baati Wolof: A Wolof Dictionary (revised edition). Los Angeles: Department of Linguistics, University of California. [UCLA occasional papers in linguistics, number 19]

Norvig, Peter. 1988. Interpretation Under Ambiguity. In Shelly Axmaker, Annie Jaisser, \& Helen Singmaster, eds., Proceedings of the Fourteenth Annual Meeting of the Berkeley Linguistics Society. 188-201

Núñez, Rafael \& Eve Sweetser. 2006. With the Future Behind Them : Convergent Evidence From Aymara Language and Gesture in the Crosslinguistic Comparison of Spatial Construals of Time. Cognitive Science, 30(3), 401-450.

Radden, Günter. 2002. How metonymic are metaphors? In Dirven \& Pörings (eds). 407-434.

Sauvageot, Serge. 1965. Description synchronique d'un dialecte wolof: le parler du Dyolof. Dakar: IFAN (Institut Fondamental d'Afrique Noire.)

Slobin, Dan. 2003. The Many Ways to Search for a Frog: Linguistic Typology and the Expression of Motion Events. In S. Strömqvist \& L. Verhoeven, eds., Relating Events in Narrative: Typological and Contextual Perspectives. Mahwah NJ: Lawrence Erlbaum Associates.

Sweetser, Eve. 1988. Grammaticalization and Semantic bleaching. In Shelley Axmaker, Annie Jaisser, and Helen Singmaster, eds., Proceedings of the Fourteenth Annual Meeting of the Berkeley Linguistics Society. 389-405.

Traugott, Elizabeth Closs. 1975. Spatial Expressions of Tense and Temporal Sequencing: A Contribution to the Study of Semantic Fields. Semiotica 15, 207-230. Mouton Publishers.

Whorf, Benjamin Lee. 1956. Language, Thought, and Reality: Selected Writings of Benjamin Lee Whorf (ed. J.B. Carroll). Cambridge: The MIT Press.

Kevin Moore

Linguistics and Language Development

San José State University

1 Washington Square

San José, CA 95192-0093

kmoore3@email.sjsu.edu 